\title{
Gebelikte Uterin Anomaliye Yaklaşım: Olgu Sunumu ve Derleme
}

\author{
Management of Uterine Anomaly in Pregnancy: Case Report and Review \\ Mustafa TEKİN ${ }^{1}$, Navdar Doğuş UZUN ${ }^{1}$ \\ 1. Mardin Devlet Hastanesi, Kadın Hastalıkları ve Doğum Kliniği, Uzman Doktor, Türkiye
}

\section{$\ddot{O Z Z E T}$}

Fallop tüpleri, uterus, serviks ve vajinanin $2 / 3$ proksimal kısmı Müllerian kanal yapılarından orjin almaktadır. Embriyogenezis sirasinda, Müllerian kanal gelişimindeki herhangi bir oluşacak duraklama yada bozukluk, "Müllerian Kanal Anomalileri" diye isimlendirilen uterovajinal yapısal bozukluklara neden olur. Tam olarak uterin anomalilerin popülasyon sıklığ net olarak bilinmemektedir. Overler, primitif yolk sak'tan ve üst vajina parçası, ürogenital sinüsten köken aldı ̆̆ için Müllerian Kanal Anomalileri'de dış genitallerin ve overlerin gelişim bozukluklarına rastlanmaz. Bundan dolayıdır ki dış genitalyası normal ve düzenli menstirüel siklusa sahip olan kadınlarda da uterin bozukluklar görülebilmektedir. Uterin anomaliye sahip popülasyonun gebelik gibi zor bir süreçte takip ve doğum planlanmasinda zorluklar görülmektedir.

Anahtar Kelimeler: uterin anomali, gebelik

\section{ABSTRACT}

The uterus, fallopian tubes, 2/3 proximal part of the cervix and vagina originate from the Mullerian canal structures. During embryogenesis, any pause or disorder in mullerian canal development causes uterovaginal structural disorders called "Mullerian Channel Anomalies." The population frequency (insidence) of uterine anomalies is not known exactly. Since the ovaries originate from primitive yolk sak and the upper vagina part originates from the urogenital sinus, development disorders of external genitals and ovaries are not encountered in the Mullerian Canal Anomalies. Therefore, uterine disorders can also be observed in women with normal and regular menstrual cycles. Several difficulties may be observed during the follow-up and birth planning of the pregnant women with uterine anomalies in a difficult period such as pregnancy.

Keywords: uterine anomaly, pregnancy

\section{GÍRIȘ}

Tüm kadınların yaklaşık \%10'unda konjenital uterin anomali görülmektedir. Konjenital uterin anomaliye sahip tüm kadınlar genel popülasyona göre tekrarlayan spontan düşükler ve olumsuz gebelik sonuçları açısından daha yüksek risk altındadır. Bu kadınlardan infertil olanlarına veya çok sayıda spontan düşük gerçekleştirenlerine cerrahi tedavi düşünülmelidir (1).

\section{İletişim}

Sorumlu Yazar: Navdar Doğuș UZUN, Uzm. Dr.

Adres: Mardin Devlet Hastanesi, Nur, Vali Ozan Cd., 47100 Artuklu, Mardin, Türkiye

Tel: +90 (536) 5485145

E-Posta: duzun35@hotmail.com

Makale Geliş: 25.03 .2020

Makale Kabul: 30.04 .2020

DOI: http://dx.doi.org/10.16948/zktipb.708002
Müllerian kanal anomalileri, embriyogenezis sirasinda meydana gelen anormallikler veya uterin septum füzyonundaki yetersizlikten kaynaklanan anomalilerdir. $\mathrm{Bu}$ problem yüzyıllardır bilinmektedir. Eğer ileri düzeyde bir anomali yada uterus da yapisal bozukluk ileri derecede kaviteyi etkilemiyor ise gebelik genellikle doğum ile sonuçlanmaktadır. Ancak uterin anomalisi olan kadınların gebeliklerinin takip ve doğum şekilleri açısından pluşturulmuș net bir konsensus yoktur (2).

\section{OLGU}

21 yaşında, gravida 2, parite 1 bayan hasta 37 haftalık gebelik, her iki gebelik arasında 5 aylık bir süre mevcut, aktif amniyon mai gelişi ve eski sezaryen ön tanısı ile kliniğimize dış merkezden sevk ile refere edildi. Muayenesinde $4 \mathrm{~cm}$ servikal açıklık ve yaklaşık yüzde 40 - 50 efesman izlendi. Yapılan ultrasonografik incelemede 37 hafta ile uyumlu makat geliş canlı tek fetüs izlendi. Hastadan edinilen anamnez de ise ilk gebeliğinde yine 37 haftada makat geliş ve aktif amniyon mai gelişi olması üzerine gebeliği sezaryen ile sonlandırılmıș. İlk gebeliğindeki fetüs hayatta ve herhangi bir hastallk ve sıkıntı yaşamamış. İnspeksiyon da ise uterus sola deviye gergin olarak izlendi. Bu gebeliğinde düzenli olarak doktora gitmediği ve ek hastalığının olmadığı öğrenildi. Hastanın sekonder seks karakterleri doğal olarak değerlendirdi.

Hasta acil şartlarda sezaryene alındı. Hastaya acil şartlarda spinal anestezi uygulandi. Periton geçilip batına girildiğinde ise uterus dış morfolojik olarak "Unicornuate Uterus" olarak düşünülüp , sol laterale deviye olarak izlendi. El ile manipüle edilerek uterus orta hatta getirildi, Kerr insizyon ile uterus geçildikten sonra anhidroamniyos ve makat geliş hali izlendi.

Fetus uterus yan duvarlara kenetlenmiş el ile manipüle edilemedi. Fetus dışarı alınmış, o sırada sağ femur bölgesinden ses gelmesi üzerine doğum sırasında bebeği teslim alan pediatri hekimine durum bildirildi. Plasenta harice alındı. Plasenta yapisinda ek bir patoloji ve morfolojik bozukluk izlenmedi. Uterin insizyon hatt1 dikildikten sonra her iki tuba ve overler değerlendirildi ancak sol tuba ve sol over ilk bakışta görülemedi. Ekartör ile görüş alanı arttırılıp değerlendirildiğinde ise sol uterus yarımının rudimente olarak izlendiği sol tubanın, bu rudimente uterus yarımına bağlandığ 1 , yapı olarak normal olduğu ve sol overin de tubanın distalinde doğal olarak izlendiği anlaşıldı. Rudimente sol uterus yarımının fibröz bir yapı ile diğer uterin yarıma serviks hizasından bağl1 olduğu görüldü. 


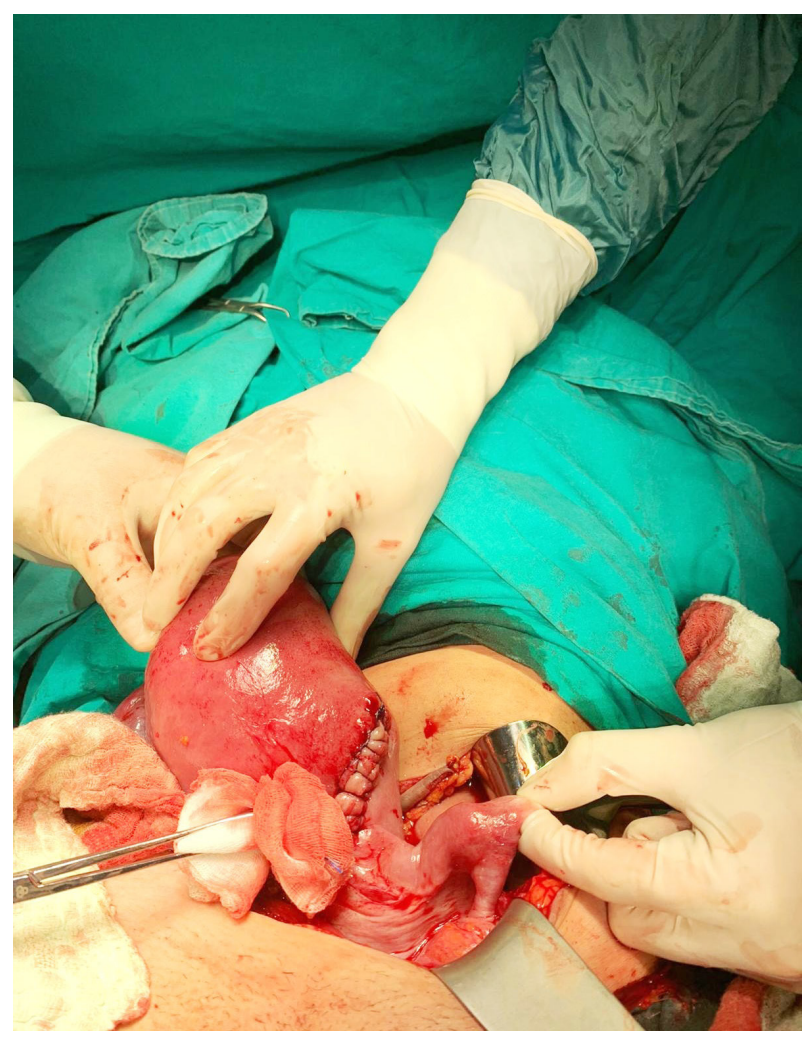

Resim 1: Uterus yarımlarının fibröz doku ile bağlantısı.

Sağ uterin yarımı ise sağ yana deviye normalden küçük olarak izlendi (Resim 1). Sol rudimente uterin yarımının ise vajene doğru kendi servikal çıkıntısı olduğu izlendi. Postpartum uterin kas kitlesi atonik değil idi ve uterotonik ajanlara doğal cevap verdi.

Post partum hastada kanama izlenmedi. Ancak yenidoğan bebek değerlendirildiğinde ise sağ femurda krepitasyon alınmakta idi. Çekilen direkt grafide ise femur şaft kırığ 1 görüldü (Resim 2).

Yenidoğan bebek 20 dakika içinde ortopedi kliniğinde değerlendirilip, sağ bacağa alçı uyguland1.

Postpartum hastaya ilk ameliyatı sorulduğunda ise, ilk gebelikte geçirmiş olduğu sezaryen ile ilgili kendisine ek bilgi verilmediğini ve doğumundan 5 ay sonra tekrardan gebe kaldığını belirtti. Hasta evliliğinde herhangi bir infertilite sorunu yaşamağ için ek tetkik yaptırılmamıştı. Hasta postpartum 48. saatte şifa ile taburcu edildi.

\section{TARTIŞMA}

Müllerian kanal birleşme anomalisi olan hastaların fertilite ve gebelik sonuçlarının normal popülasyona göre daha sık sorunlar yaşadıkları bilinmektedir. Tekrarlayan gebelik kaybı olan kadınlarda normal toplum istatistiklerine bağlı olarak üç kat daha fazla uterin anomali görülmektedir. Prematür doğum, erken membran rüptürü, primer amenore, infertilite, endometriozis, tekrarlayan spontan düşükler, fetal intrauterin gelişim geriliği, fetal malpozisyon, erken doğum ve rest plasenta insidansı artmıştır (3). Bu uterin anomalilerde erken doğumu önlemek için servikal serklaj önerilmektedir ancak ilk gebeliklerde tanı alması zor olacağ 1 için diğer gebeliklerinde bu karar verilebilinir. Diğer anomali-

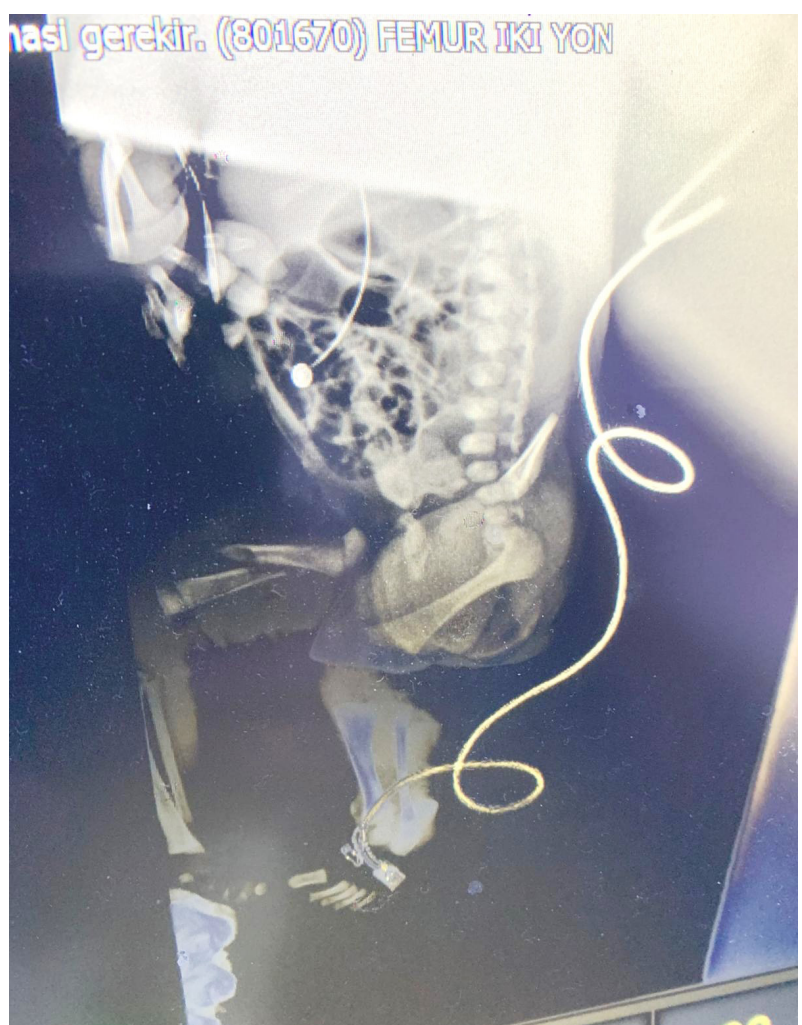

Resim 2: Yenidoğanda sağ femur şaft kırı̆̆ı.

lere göre uterin didelfisi olan hastalarda, reprodüktif sonuçlar daha iyidir.

Menstruasyon düzensizlikler diğer anomalilerine göre daha azdır ve beklenilenin aksine dismenoreik şikayetler şiddetli değildir. Ancak adolesan yaşta görülen endomeriozis olgularında genital sistem anomalileri akla getirilmelidir.

Uterin anomaliler, gebelerde bir çok obstetrik ve jinekolojik komplikasyona sebep olmaktadır. Her iki over dokusunun embriyonal kaynağı müllerian kanallardan farklı olduğu için çoğunlukla, over dokusu korunmuş ve fonksiyonel olarak normaldir. Her ay olan mens döngüsünde doğal işlevini görmektedir. Uterusun orta hatta füzyonu ürogenital trakt ile birleşmesin de ya da uterin septumun rezorbsyonunda görülen duraklama - kesintiler uterogenital trakta anomali tablosu ile kendini klinikte göstermektedir. Görüntüleme yöntemleri ile bunların tanısı konulabilir. Bunun için Ultrasonografi (USG) ve Magnetik Rezonans Görüntüleme (MRG) kullanılabilinir. Fetal iyilik hali gözetileceği için Bilgisayarlı Tomografi (BT) ve kontrast madde kullanılamamaktadır. Müllerian kanal anomalisi olan kadınlarda ürogenital anomali görülme sıklığı artt1ğ için, böbrek ve üriner toplayıcı sistem kesinlikle araştırılmalıdır. Transvaginal ultrasonografi, özellikle üç boyutlu görüntüleme ile uterin anomalilerin saptanmasında kolaylık sağlamaktadır (4).

Uterin anomaliler nadir görülen, gebelerde birçok obstetrik komplikasyona neden olabilen bir malformasyon olup, gebelerin dikkatli takip ve tedavi edilmeleri gerekmektedir. Bu vaka özelinde olduğu gibi bir önceki cerrahisinde hastaya bilgi verilmediği ve hasta başka bir kurumda sezaryan olduğu için yapılan cerrahide riskler ve komplikasyonların oranı artmaktadır. Ayrıca rudimenter hornun ağrıya neden olabileceği ve eksizyona kadar gidebileceği 
yönünde bir görüște vardır. Rudimenter dokunun çoğunlukla afonksiyonel doku içermesinen dolayı çoğunlukla ağrı ve ek semptomlar sergilemez. Ancak bu vaka özelinde rudimenter bölge eksize edilmedi.

Anne ve fetal iyilik hali için anneye yapılan cerrahi hakında bilgi verilmesi bir sonraki gebeliğinde takip ve doğumda görülebilecek komplikasyon oluşmasını azalmakta ve doğum planlanmasında yön veren önemli bir detaydır.

Hastaların ilerleyen zaman diliminde tekrar uygulanacak ya da geçireceği acil cerrahiler öncesinde cerrahın bilmesi gereken durumlar böylece anlaşlacak ve yapılacak olan ameliyat daha sihhatli ve komplikasyonsuz olacaktır. Türkiye sağlık siteminde ortak bir paylaşım ve tüm hekimlerin kullandığı ortak bir hasta takip sistemi olması acil yapılacak cerrahi öncesinde doktora bilgi verecek detaylara ulaşımını sağlayacaktır.

Uterin anomalilerde kabul edilmis ortak bir tedavi ve belirgin bir cerrahi önerisi yoktur. Hasta ve anomali tipine yönelik bireysel bir yaklaşım çoğunlukla yapılmaktadır.

Ayrıca bu olgu özelinde düsünüldüğünde ise yenidoğan döneminde doğum travmaları içerisinde femur kırığı nadir görülmektedir. Doğum travması gelişimi açısından risk faktörleri; fetusa - anneye ait ve diğer faktörler olarak gruplanabilir. Ayak prezentasyonu, malprezentasyon ya da çok nadir görülen Jarcho - Levin sendromu gibi hastalıklar, kas iskelet sistem hastalıkları femur kırığının oluşma riskini arttırmaktadır (5).

Sonuç olarak bu olgu ile uterin anomali ve doğumda görülebilecek olan komplikasyonlar açısından riskli doğumların önceden belirlenerek doğuma uygun şekilde hazırlık yapılması gerektiği vurgulanmak istendi.

\section{KAYNAKLAR}

1. Venetis CA, Papadopoulos SP, Campo R, Gordts S, Tarlatzis BC, Grimbizis GF. Clinical implications of congenital uterine anomalies: a meta-analysis of comparative studies. Reprod Biomed Online. 2014 Dec;29(6):665-83.

2. Mørk N, Lauszus FF, Agha Krogh RH. Congenital uterine anomalies and their association with fertility and pregnancy outcomes Ugeskr Laeger. 2018 Oct 1;180(40)

3.Simon C, Martinez L, Pardo F, Tortajada M, Pellicer A: Mullerian defects in women with normal reproductive outcome. Fertil Steril. 56:1192-93, 1991.

4.Ural ÜM, Gungör T, Neslihanoğlu R, Mollamahmutoğlu L: Uterin didelfis olgusunda eş zamanl gebelik ve RIA: Olgu Sunuти. Duzce Tıp Fakültesi Dergisi. 3:28-29, 2005.

5.Alper Çıraklı, Murat Erdoğan, Sevgi Çırakll, Hicabi Sezgin, Fatma Çakmak Çelik, Canan Aygün ; Bilateral Femoral Fractures in the Neonate with Jarcho-Levin Syndrome; JOPP Derg 5(3):145-147, 2013 